\title{
A trans-Coplanar Elimination of Sulfur Dioxide and Chloride
}

\section{Ion in 2-Chloroalkanesulfinates*}

\author{
TOMAS KEMPE and TORBJÖRN NORIN
}

Department of Organic Chemistry, Royal Institute of Technology, S-100 44, Stockholm 70, Sweden

2-Chloroalkanesulfinates are shown to decompose into alkenes, sulfur dioxide, and chloride ions. The mechanism of the reaction is discussed. The reaction is shown to proceed via a trans. coplanar elimination. The possible implication of a 2-substituted alkanesulfinate in the basepromoted rearrangement of $\alpha$-halosulfones (Ramberg-Bäcklund rearrangement) is discussed.

The decomposition of a 2-haloalkanesulfinate has not previously been studied. However, it is known 1 that the barium salt of 2-hydroxyethanesulfinic acid decomposes to yield ethylene and barium sulfite. During the course of this work the decomposition of perfluoroalkanesulfinates to yield perfluoroalkenes has been reported..$^{2}$ It is also of interest to note that a 2-halosulfinate has been discussed ${ }^{3}$ as an intermediate in the base-induced rearrangement of $\alpha$-halosulfones to alkenes (Ramberg-Bäcklund rearrangement).

In connection with a study of sulfur dioxide elimination reactions, 2-chloroethanesulfinic acid was treated with base. The sulfinate was found to decompose spontaneously to ethylene, chloride ion, and sulfur dioxide in good yield (Scheme I). In this paper the decomposition of 2-chloroalkanesulfinates will be discussed and evidence for a trans-coplanar elimination will be presented.

2-Chloroethanesulfinate (1) is readily available and has been used as a model compound for kinetic and mechanistic studies. This

* Kempe, T. and Norin, T., presented in part at the "14de Nordiska Kemistmötet", Umeà, June 1971: "Vth Symposium on Organic Sulphur Chemistry", Lund, June 1972. compound was prepared from the corresponding sulfinyl chloride which may be prepared by addition of thionyl chloride to ethylene according to a previous method." A more convenient method for the preparation of 2-chloroethanesulfinyl chloride has now been developed. Treatment of ethylene sulfide and acetic anhydride in equivalent amounts with chlorine afforded 2-chloroethanesulfinyl chloride in good yield. The corresponding sulfinic acid was prepared by a careful hydrolysis with aqueous sodium hydrogen carbonate followed by acidification with sulfuric acid. The 2-chloroethanesulfinic acid was extracted with ethyl ether. The crude sulfinic acid, obtained after evaporation of the solvent, was found to be pure and was characterized by IR and NMR.

The decomposition of 2-chloroethanesulfinate (1) can be performed in water or in organic solvents. The rate of the decomposition in water with excess sodium hydroxide has been determined. The formation of ethylene was found to follow first order kinetics and the activation energy of the reaction was $127.8 \pm 8.4$ $\mathrm{kJ} \mathrm{mol}^{-1}$.

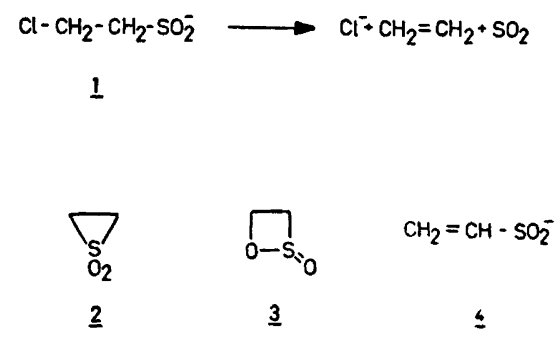

Scheme 1.

Acta Chem. Scand. B 28 (1974) No. 6 
Different reaction mechanisms for the decomposition reaction can be formulated. Ethylene sulfone (2) can be ruled out as an intermediate since this compound was found to be stable under the reaction conditions used. A less probable intermediate is 1,2-oxathietane 2 -oxide $\left(3, \beta\right.$-sultine). $\beta$-Sultines are known ${ }^{5}$ to decompose to alkanes and sulfur dioxide. However, they also react with alcohols to give 2-hydroxyalkanesulfinic acid esters. ${ }^{5}$

When the decomposition of 2-chloroethanesulfinate was carried out in methanol in the presence of triethylamine, no methyl 2-hydroxyethanesulfinate could be detected in the reaction product.

When the decomposition of 2-chloroethanesulfinate was performed in a deuterium oxide solution, no deuterium incorporation could be detected in the ethylene as shown by the mass spectrum of the 1,2-dibromoethane formed by bromination of the ethylene. Thus ethylenesulfinate (4) derived from the 2-chloroethanesulfinate by hydrogen chloride elimination, cannot be an intermediate in the reaction.

The most likely mechanism for the 2halosulfinate decomposition is a trans-coplanar elimination of sulfur dioxide and chloride ion. In order to obtain additional information regarding this reaction its stereochemistry was investigated as follows.
The addition of sulfur monochloride to alkenes is known to proceed via a trans-addition yielding the corresponding 2-haloalkyl disulfides $^{\circ}$ (Scheme 2). Lautenschlaeger and Schwartz have recently shown ${ }^{6}$ that the addition to cis-2-butene yields bis(threo-2-chloro-1methylpropyl)disulfide (threo-5) which upon treatment with sodium sulfide gives the cis-2,3dimethylthiirane (6). The corresponding trans2-butene yields the trans-2,3-dimethylthiirane under similar conditions.

We have reacted cis-2-butene with sulfur monochloride. The disulfide (threo-5) thus obtained was oxidized with chlorine in acetic anhydride to yield the corresponding threo-2chloro-1-methylpropanesulfinyl chloride (threo7) by a known reaction.? This compound was hydrolysed with aqueous sodium hydroxide. The intermediate threo-2-chloro-1-methylpropanesulfinate (threo-8) rapidly decomposed to yield cis-2-butene. Less than $1 \%$ trans-2butene was present in the product as shown by gas chromatography.

Similarly trans-2-butene yielded erythro-2. chloro-1-methylpropanesulfinyl chloride (erythro7) which, without isolation, was treated with aqueous sodium hydroxide to yield trans-2butene via the intermediate erythro-2-chloro-1methylpropanesulfinate (erythro-8). Less than $1 \%$ cis-2-butene was present in the product.

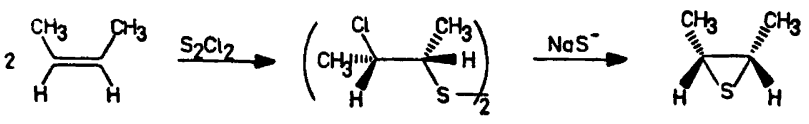

threo- -5

$\underline{6}$

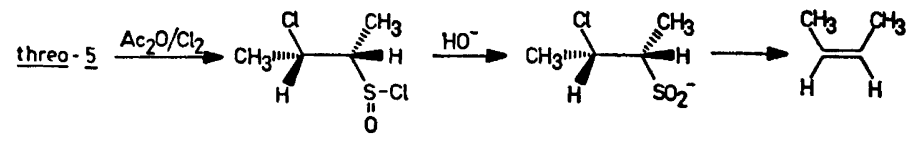

threo $-\underline{7}$ threo-

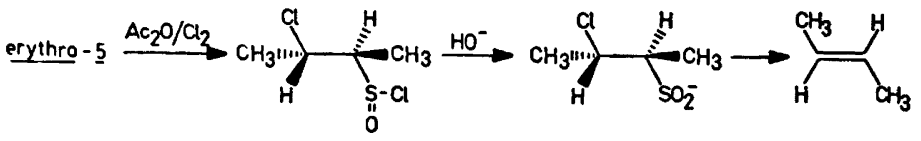

erythro - ?

erythro-

Scheme 2. 
The 2-halosulfinate decomposition is thus a stereospecific reaction and the results presented above support a mechanism involving a trans. coplanar elimination.

A 2-chloroalkanesulfinate decomposition also occurs with 2,2,2-trichloroethanesulfinate ( 9 , Scheme 3). When the sulfinyl chloride of 9 was hydrolysed with an equivalent amount of aqueous sodium hydroxide, 1,1-dichloroethylene (12) was formed. With an excess of sodium hydroxide, chloroacetylene (13) was isolated in addition to dichloroethylene (12). Two possible routes for the formation of chloroacetylene may be considered. In one the 2,2-dichloroethylenesulfinate intermediate (10) decomposes via a reaction mechanism similar to that for the 2halosulfinate and in the other, further dehydrohalogenation of the 2,2-dichloroethylenesulfinate (10) gives 2-chloroacetylenesulfinate (11) which decomposes into chloroacetylene (13) and sulfur dioxide.

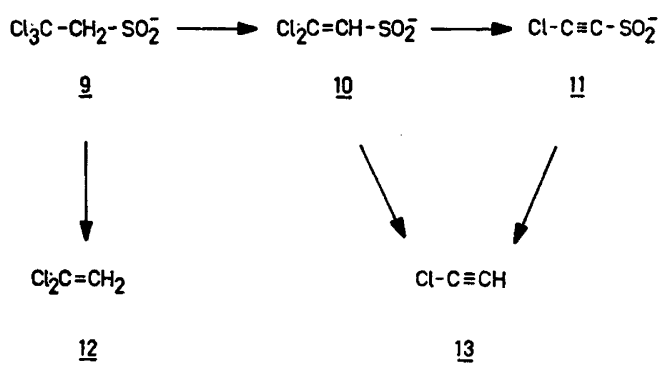

Scheme 3.

There is strong evidence for the presence of intermediate thiirane 1,1-dioxides in the baseinduced rearrangement of $\alpha$-halosulfones (Ramberg-Bäcklund rearrangement). ${ }^{\circ}$ The decomposition of this intermediate thiirane 1,1dioxide to alkene and sulphur dioxide is a stereospecific reaction ' (Scheme 4). Although this decomposition is known to be a thermal reaction it is not clear whether the base, in some cases, may take part in the decomposition. It has been established that ethylene sulfone upon treatment with alkali yields 2hydroxyethanesulfinate. ${ }^{1}$ Hence nucleophilic attack of the base on the intermediate thirane 1,1-dioxide in the Ramberg-Bäcklund rearrangement should yield 2-substituted alkanesulfinates. This reaction has been discussed by
Bordwell et al.10 They propose that an intermediate 2-methoxyalkanesulfinate would appear to be stable under conditions whereby thiirane 1,1-dioxides are converted to alkenes. Therefore, they conclude that this mechanism does not operate in the decomposition of thiirane 1,1-dioxides in the presence of methoxide ions. However, there are no indications that alkanesulfinates with a leaving group in 2-position are stable under the conditions for a RambergBäcklund rearrangement and the formation of an intermediate 2-substituted alkanesulfinate cannot be excluded. This intermediate would then decompose by a reaction analogous to the stereospecific decomposition of 2-chloroalkanesulfinates (Scheme 4).

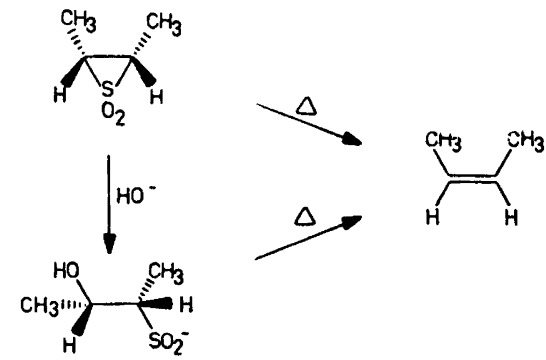

Scheme 4.

\section{EXPERIMENTAL}

All boiling points are uncorrected. IR spectra were measured on a Perkin Elmer Model 421 infrared spectrophotometer. NMR spectra (TMS internal standard) were recorded on a Varian Model A-60A instrument. Mass spectra were obtained using an LKB Model 9000 mass spectrometer.

2-Chloroethanesulfinyl chloride. A solution of ethylene sulfide $(23.5 \mathrm{~g}, 0.39 \mathrm{~mol})$ and acetic anhydride (40 g, $0.39 \mathrm{~mol})$ was cooled to 5 ${ }^{\circ} \mathrm{C}$. Chlorine was than passed into the solution at such a rate that the temperature remained between 10 and $15^{\circ} \mathrm{C}$. When no more chlorine was consumed excess chlorine and acetyl chloride was removed by evaporation in vacuo at room temperature. The residue was distilled at reduced pressure to give 2-chloroethanesulfinyl chloride; b.p. $42^{\circ} \mathrm{C} / 0.7 \mathrm{mmHg}$ (lit. ${ }^{\prime}$ b.p. $81^{\circ} \mathrm{C} / 9 \mathrm{mmHg}$ ); yield $46 \mathrm{~g}(80 \%)$; IR (film) $1150 \mathrm{~cm}^{-1}(\mathrm{~S}=\mathrm{O}) ; \mathrm{NMR}\left(\mathrm{CDCl}_{3}\right) \delta 3.95 \mathrm{ppm}$ $\left(\mathrm{m}, \mathrm{CH}_{2}\right.$ ).

2-Chloroethanesulfinic acid. 2-Chloroethanesulfinyl chloride $(14.7 \mathrm{~g}, 0.1 \mathrm{~mol})$ was slowly added to an aqueous solution $(100 \mathrm{ml})$ of sodium hydrogen carbonate $(16.8 \mathrm{~g}, 0.2 \mathrm{~mol})$ cooled to $5^{\circ} \mathrm{C}$. The mixture was stirred for $10 \mathrm{~min}$ and

Acta Chem. Scand. B 28 (1974) No. 6 
then acidified with conc. sulfuric acid (10 g). The 2-chloroethanesulfinic acid thus formed was extracted with ethyl ether $(200 \mathrm{ml})$. The solution was dried and the solvent evaporated in vacuo to give the oily 2-chloroethanesulfinic acid; yield $9 \mathrm{~g}(70 \%)$; IR (film) 1080 (broad) $\mathrm{cm}^{-1}\left(\mathrm{SO}_{2} \mathrm{H}\right) ; \mathrm{NMR}\left(\mathrm{CDCl}_{3}\right) \delta 3.2\left(t, 2, \mathrm{CH}_{2}\right)$ and $3.9 \mathrm{ppm}\left(\mathrm{t}, 2, \mathrm{CH}_{2}\right)$.

Decomposition of 2-chloroethanesulfinic acid in the presence of sodium hydroxide. 2-Chloroethanesulfinic acid (8 $\mathrm{g}, 0.062 \mathrm{~mol}$ ) was added to an aqueous sodium hydroxide solution (2 $\mathrm{M}, 100 \mathrm{ml}$ ). The reaction mixture was slowly heated to $60^{\circ} \mathrm{C}$ and was then kept at that temperature for $10 \mathrm{~min}$. The ethylene thus formed was passed through a chloroform solution $(100 \mathrm{ml})$ containing bromine $(16 \mathrm{~g}, 0.1$ mol). The chloroform solution was treated with an aqueous sodium bisulfite solution $(10 \%)$ in order to remove unreacted bromine, washed with water and dried. Evaporation of the solvent afforded crude 1,2-dibromoethane; b.p. $131-132{ }^{\circ} \mathrm{C} / 760 \mathrm{mmHg}$; yield $4 \mathrm{~g}(34 \%)$; $n_{\mathrm{D}}{ }^{22} 1.5360$. The 1,2-dibromoethane was analysed by GLC-MS (column, $150 \mathrm{~cm} \times 3 \mathrm{~mm}$, packed with $5 \%$ SE 30 on Chromosorb W $60 / 80$ mesh, column temperature $\left.70^{\circ} \mathrm{C}\right), \mathrm{m} / \mathrm{e}$ (rel. intensity); $\mathrm{C}_{2} \mathrm{H}_{4} \mathrm{Br}^{+}$107(100), 109(100); $\mathrm{C}_{2} \mathrm{H}_{4} \mathrm{Br}_{2}+\cdot 186(1.3), 188(2.6), 190(1.3)$.

Decomposition of 2-chloroethanesulfinyl chlo. ride in the presence of $\mathrm{D}_{2} \mathrm{O} / \mathrm{NaOD}$. 2-Chloroethanesulfinyl chloride (1 $\mathrm{g}, 6.8 \mathrm{mmol})$ was added to a sodium deuterium oxide solution (1 M, $15 \mathrm{ml}$ ) in deuterium oxide. The mixture was heated to ensure decomposition of 2-chloroethanesulfinate. The ethylene gas was passed through a chloroform solution containing bromine to give 1,2-dibromoethane. The excess of bromine was removed in the usual way. The 1,2-dibromoethane was analysed by GLC.MS as has been described above. No deuterated 1,2-dibromoethane could be detected in the reaction mixture. The mass spectrum of the product was identical with that of an authentic sample of 1,2-dibromoethane.

Decomposition of 2-chloroethanesulfinic acid in the presence of ethylene sulfone. The NMR spectrum of 2-chloroethanesulfinic acid in chloroform solution exhibits peaks at $\delta 3.2$ $\left(t, 2, \mathrm{CH}_{2}\right), 3.9\left(t, 2, \mathrm{CH}_{8}\right)$ and $7.4 \mathrm{ppm}(\mathrm{s}$, $\mathrm{SO}_{2} \mathrm{H}$ ). When excess pyridine is added to the sulfinic acid, gas is evolved. The peaks at $\delta$ 2.93 and $3.85 \mathrm{ppm}$ of 2-chloroethanesulfinate decrease. 2-Chloroethanesulfinate disappeared after $18 \mathrm{~min}$ and no other peaks except that of ethylene $(\delta 5.22 \mathrm{ppm})$ could be detected in this region. Ethylene sulfone ${ }^{11}(\delta 3.12 \mathrm{ppm})$ was found to be stable in pyridine/chloroform solution under the condition used. No appreciable decrease of the peak at $\delta 3.12 \mathrm{ppm}$ was observed after 1 h. 2-Chloroethanesulfinic acid and ethylene sulfone were mixed in a chloroform solution. Excess pyridine is then added and the decomposition of 2-chloroethanesulfinate is followed by NMR. When the 2-chloroethane- sulfinate is completely consumed (ca. $20 \mathrm{~min}$ ) the intensity of the peak from the ethylene sulfone $(\delta 3.12 \mathrm{ppm})$ is still undiminished.

Decomposition of 2-chloroethanesulfinate in the presence of methanol. Triethylamine $(2 \mathrm{~g}, 0.02$ $\mathrm{mol}$ ) was added to a solution of 2-chloroethanesulfinic acid $(2.5 \mathrm{~g}, 0.02 \mathrm{~mol})$ in methanol $(40$ $\mathrm{ml}$ ) at room temperature. The reaction mixture was then boiled for $30 \mathrm{~min}$. The presence of sulfur dioxide could be detected by the characteristic smell of the gas. The volatile constituents in the solution were then evaporated in vacuo to give a crystalline residue which was washed several times with ethyl ether. The combined ether solutions were washed with water and dried. Evaporation of the solvent under reduced pressure did not afford any residue. The insoluble crystals which did not dissolve in ethyl ether was characterized as triethylammonium chloride which upon treatment with alkali gave triethylamine. This experiment shows that methanol does not react with any intermediate (e.g. $\beta$-sultine) during the decomposition of 2-chloroethanesulfinate and it is thus unlikely that any such intermediate is involved in the decomposition reaction.

Bis (2,2,2-trichloroethyl)disulfide was prepared essentially according to the method of Aichenegg.12 Sulfur monochloride $(81 \mathrm{~g}, 0.6 \mathrm{~mol})$ was added dropwise over $2 \mathrm{~h}$ to a mixture of 1,1-dichloroethylene $(250 \mathrm{~g}, 2.58 \mathrm{~mol})$ and $\mathrm{FeCl}_{3}$ $(8 \mathrm{~g})$. The reaction mixture was kept at room temperature overnight and was then diluted with I vol of acetone, followed by addition of sufficient water to give 2 layers. The organic phase was recovered and washed with water. The procedure was repeated until no more acetone was present in the organic phase, which was then dried and evaporated in vacuo to give a residue. Distillation at reduced pressure afforded bis(2,2,2-trichloroethyl)disulfide; b.p. $122^{\circ} \mathrm{C} / 0.5 \mathrm{mmHg}$ (lit. ${ }^{12}$ b.p. $145-150^{\circ} \mathrm{C} / 0.36-$ $0.46 \mathrm{mmHg})$; yield $90 \mathrm{~g}(46 \%) ; n_{\mathrm{D}}{ }^{25} 1.5750$ (lit. $\left.{ }^{12} n_{\mathrm{D}}{ }^{20} 1.5780\right)$.

2,2,2-Trichloroethanesulfinyl chloride. A solution of bis $(2,2,2$-trichloroethyl)disulfide $(32.8 \mathrm{~g}$, $0.1 \mathrm{~mol})$ and acetic anhydride $(20.4 \mathrm{~g}, 0.2 \mathrm{~mol})$ was cooled to $5^{\circ} \mathrm{C}$. Chlorine was then passed into the solution at such a rate that the temperature remained between 10 and $15^{\circ} \mathrm{C}$. When no more chlorine was consumed, chlorine and acetyl chloride were removed by evaporation in vacuo at room temperature. The residue was distilled at reduced pressure to give $2,2,2$ trichloroethanesulfinyl chloride; b.p. $56{ }^{\circ} \mathrm{C} / 1.5$ $\mathrm{mmHg}$; yield $32 \mathrm{~g}(74 \%) ; n_{\mathrm{D}}{ }^{25} 1.5446 ;$ IR (film) $1160 \mathrm{~cm}^{-1}(\mathrm{~S}=\mathrm{O})$; $\mathrm{NMR}$ (neat) $\delta_{\mathrm{A}} 4.68$ and $\delta_{\mathrm{B}} 4.85 \mathrm{ppm}\left(J_{\mathrm{AB}} 14 \mathrm{~Hz}\right)$.

Decomposition of 2,2,2-trichloroethanesulfinyl chloride with an equivalent amount of base. An aqueous sodium hydroxide solution (1.6 M, $50 \mathrm{ml}$ ) was slowly added to a cooled mixture $\left(5{ }^{\circ} \mathrm{C}\right)$ of 2,2,2-trichloroethanesulfinyl chloride $(8.6 \mathrm{~g}, 0.04 \mathrm{~mol})$ and water $(150 \mathrm{ml})$. Carbon tetrachloride $(50 \mathrm{ml})$ was then added to dissolve 
the 1,1-dichloroethylene formed. The reaction mixture was then kept at room temperature for $2 \mathrm{~h}$. The NMR spectrum of the carbon tetrachloride solution shows that 1,1-dichloroethylene was formed in $53 \%$ of the theoretical yield (determined by using a reference solution of 1,1-dichloroethylene in $\left.\mathrm{CCl}_{4}\right)$. 1,1-Dichloroethylene; IR $\left(\mathrm{CCl}_{4}\right) 1610 \mathrm{~cm}^{-1}(\mathrm{C}=\mathrm{C})$; NMR $\left(\mathrm{CCl}_{4}\right) \delta 5.5 \mathrm{ppm}\left(\mathrm{s}, \mathrm{H}_{2} \mathrm{C}=\right)$.

Decomposition of 2,2,2-trichloroethanesulfinyl chloride in excess base. To an aqueous sodium hydroxide solution (1 M, $200 \mathrm{ml}$ ) and carbon tetrachloride $(5 \mathrm{ml})$ was slowly added 2,2,2trichloroethanesulphinyl chloride $(4.3 \mathrm{~g}, \quad 0.02$ mol). The reaction mixture was kept during 2 $h$ at room temperature under nitrogen. Air must be excluded owing to the explosive nature of chloroacetylene in the presence of oxygen. The IR and NMR spectra of the carbon tetrachloride solution showed that chloroacetylene was formed together with 1,1-dichloroethylene. The yield of chloroacetylene was not determined. Chloroacetylene; IR $\left(\mathrm{CCl}_{4}\right) 3300$ (CH) and $2100 \mathrm{~cm}^{-1}(\mathrm{C} \equiv \mathrm{C})$; NMR $\left(\mathrm{CCl}_{4}\right) \delta 1.78 \mathrm{ppm}$ (s, CH). 1,1-Dichloroethylene was treated with a sodium hydroxide solution under the conditions described above. Chloroacetylene could not be detected in this experiment.

Bis(threo-2-chloro-1-methylpropyl)disulfide from cis-2-butene and sulfur monochloride. ${ }^{6}$ cis-2Butene (35 g) was added to a solution of $\mathrm{FeCl}_{3}$ $(1 \mathrm{~g})$ in ethyl ether $(150 \mathrm{ml})$. Sulfur monochloride $(27 \mathrm{~g}, 0.2 \mathrm{~mol})$ was then slowly added to the stirred solution over $30 \mathrm{~min}$. cis-2-Butene was passed continuously through the reaction mixture to maintain an excess. The reaction mixture was stirred at room temperature for 3 $h$ after addition of sulfur monochloride and then washed with water. The organic phase was dried and the solvent removed in vacuo. The residue was distilled under reduced pressure and a fraction was collected at b.p. $80-83{ }^{\circ} \mathrm{C} / 0.2$ $\mathrm{mmHg}$; yield $19 \mathrm{~g}$. Without further purification this fraction was used in the preparation of threo-2-chloro-1-methylpropanesulfinyl chloride (see below).

threo-2-Chloro-1-methylpropanesulfinyl chloride. A solution of bis(threo-2-chloro-1methylpropyl)disulfide $(18.5 \mathrm{~g}, 0.075 \mathrm{~mol}$, a mixture of meso and racemic forms) and acetic anhydride $(15.3 \mathrm{~g}, 0.15 \mathrm{~mol})$ was cooled to $5^{\circ} \mathrm{C}$. Chlorine was passed into the solution at such a rate that the temperature remained between 10 and $15^{\circ} \mathrm{C}$. When no more chlorine was consumed, chlorine and acetyl chloride were removed by evaporation in vacuo at room temperature. The residue was distilled at reduced pressure to give threo-2-chloro-1-methylpropanesulfinyl chloride; b.p. $64-66^{\circ} \mathrm{C} / 2$ mmHg; yield $15 \mathrm{~g}(57 \%) ; n_{\mathrm{D}}{ }^{25} 1.5140$; IR (film) $1150 \mathrm{~cm}^{-1}$ (S=O).

Decomposition of threo-2-chloro-1-methylpropanesulfinyl chloride in the presence of sodium hydroxide. threo-2-Chloro-1-methylpropanesulfinyl chloride $(7 \mathrm{~g}, 0.04 \mathrm{~mol})$ was added at room temperature to an aqueous sodium hydroxide solution ( $2 \mathrm{M}, 100 \mathrm{ml}$ ). The butene gas thus formed was passed through a sodium hydroxide solution to remove sulfur dioxide and then collected over water in a measuring cylinder. No more gas evolution could be observed after $2 \mathrm{~h}$ at room temperature. The gas $(820 \mathrm{ml})$ was analysed at GLC (column, $4.5 \mathrm{~m} \times 3 \mathrm{~mm}$, packed with $15 \%$ dimethylsulfolane on GasChrom RZ 60/80 mesh, relative retention times trans- and cis-2-butene 1.00:1.08, column temperature $30^{\circ} \mathrm{C}$ ). cis-2-Butene was present in more than $99 \%$ purity.

Bis (erythro-2-chloro-1-methylpropyl)disulfide from trans-2-butene and sulfur monochloride. ${ }^{\circ}$ This compound was first prepared according to the procedure described for the corresponding threo-isomer. However, because of the slow reaction of trans-2-butene and sulfur monochloride under these conditions a modified procedure was used. trans-2-butene (ca. $35 \mathrm{~g}$ ) was added to a solution of chloroform $(130 \mathrm{ml})$ and pyridine $(0.2 \mathrm{ml})$. Sulfur monochloride $(20.5 \mathrm{~g}, 0.152 \mathrm{~mol})$ was then added slowly to the chloroform solution which was cooled with water. The reaction temperature was not allowed to rise above $25^{\circ} \mathrm{C}$. An excess of trans2 -butene was passed continuously through the reaction mixture. After the addition, the reaction mixture was kept at room temperature for $2 \mathrm{~h}$. The chloroform and excess trans.2. butene were removed in vacuo. It was not possible to distil the residue at reduced pressure $(0.2 \mathrm{~mm})$ owing to decomposition. The crude residue was therefore used for the preparation of erythro-2-chloro-1-methylpropanesulfinyl chloride (see below).

erythro-2-Chloro-1-methylpropanesulfinyl chloride. A solution of crude bis(2-chloro-1-methylpropyl)disulfide $(37.5 \mathrm{~g}, 0.152 \mathrm{~mol})$, prepared as described above from trans-2-butene and sulfur monochloride, and acetic anhydride (31 g, $0.304 \mathrm{~mol}$ ) was cooled to $5{ }^{\circ} \mathrm{C}$. Chlorine was then passed into the solution at such a rate that the temperature remained between 10 and $15^{\circ} \mathrm{C}$. When no more chlorine was consumed the excess chlorine and acetyl chloride was evaporated in vacuo at room temperature. The residue could not be distilled owing to decomposition. Therefore, the crude erythro-2chloro-1-methylpropanesulfinyl chloride was used for the decomposition experiment (see below) without further purification.

Decomposition of crude erythro-2-chloro-1methylpropanesulfinyl chloride in the presence of sodium hydroxide. Crude erythro-2-chloro-1methylpropanesulfinyl chloride (7 g) was decomposed as described above for the correspond. ing threo-isomer to yield trans-2-butene $(280 \mathrm{ml})$ of more than $99 \%$ purity.

Kinetic procedures. The rates of the decomposition of 2-chloroethanesulfinate have been measured at $21^{\circ} \mathrm{C}$ and $34^{\circ} \mathrm{C}$ in excess 0.5 $M$ aqueous sodium hydroxide solution. The rates for the appearance of ethylene was followed 
by collecting the gas in a measuring cylinder over water $\left(21^{\circ} \mathrm{C}\right)$.

Run a at $21^{\circ} \mathrm{C}$. 2-Chloroethanesulfinyl chloride $(1.1178 \mathrm{~g}, 7.6 \mathrm{mmol})$ was added to a sodium hydroxide solution $(0.5 \mathrm{M}, 120 \mathrm{ml})$ to give 2 chloroethanesulfinate. The solution was kept at $21^{\circ} \mathrm{C}$ and the gas was collected. Totally, 161 $\mathrm{ml}$ ethylene was evolved over $1396 \mathrm{~min}$, which corresponds to an $85 \%$ yield (correction was made for water pressure and atmosphere pressure). The rate of the decomposition was calculated from the slope of a plot of $\log [a /(a-x)]$ versus time. ( $a=$ theoretical yield of ethylene; $x=$ the ethylene gas evolved). The decomposition gave good first order kinetics up to $63 \%$ reaction. The rate at $21^{\circ} \mathrm{C}$ was $(16.1 \pm 1.5) \times 10^{-4}$ $\min ^{-1}$.

Run $b$ at $34^{\circ} \mathrm{C}$. 2-Chloroethanesulfinyl chlo. ride (1.1025 $\mathrm{g}, 7.5 \mathrm{mmol}$ ) was added to a sodium hydroxide solution $(0.5 \mathrm{M}, 120 \mathrm{ml})$. The solution was kept at $34^{\circ} \mathrm{C}$ and the ethylene gas was collected. Totally, $171 \mathrm{ml}$ ethylene was evolved over $225 \mathrm{~min}$ which corresponds to $90 \%$ yield. The rate of the decomposition was derived as described in run $a$. The decomposition gave good first order kinetics up to $75 \%$ reaction. The rate at $34{ }^{\circ} \mathrm{C}$ was $(14.7 \pm 0.7) \times 10^{-8} \mathrm{~min}^{-1}$.

The activation energy $12 \overline{7} .8 \pm 8.4 \mathrm{~kJ}$. $\mathrm{mol}^{-1}$ was obtained using the Arrhenius equation:

$\log k_{\mathrm{a}} / k_{1}=\left(\Delta H_{\mathrm{a}} / 2.303 R\right)\left[\left(T_{\mathrm{z}}-T_{1}\right) / T_{\mathrm{a}} T_{1}\right]$

where $k$ is the rate constant, $\Delta H_{\mathrm{a}}$ the activation energy, $R=8.314 \mathrm{~J} \mathrm{deg.}{ }^{-1} \mathrm{~mol}^{-1}$ and $T=$ absolute temperature.

Acknowledgements. Financial support from The Swedish Natural Science Research Council is gratefully acknowledged. We also wish to thank Casco AB for support during the early stages of this investigation.

\section{REFERENCES}

1. Hesse, G., Reichold, E. and Majmudar, S. Chem. Ber. 90 (1957) 2106.

2. Harzdorf, C., Meussdoerffer, J. N., Niederprüm, H. and Wechsberg, M. Justus Liebigs Ann. Chem. (1973) 33.

3. Neureiter, N. P. and Bordwell, F. G. $J$. Amer. Chem. Soc. 85 (1963) 1209.

4. Titov, A. I. and Baryshnikova, A. N. Dokl. Akad. Nauk SSSR 157 (1964) 139.

5. Jung, F., Sharma, N. K. and Durst, T. $J$. Amer. Chem. Soc. 95 (1973) 3420.

6. Lautenschlaeger, F. and Schwartz, N. V. J. Org. Chem. 34 (1969) 3991.

7. Douglass, I. B. and Norton, R. V. J. Org. Chem. 33 (1968) 2104.

8. Carpino, L. A. and Rynbrandt, R. H. $J$. Amer. Chem. Soc. 88 (1966) 5682.

9. For recent surveys of the Ramberg. Bäcklund rearrangement see Paquette, $\mathbf{L}$. A. In Thyagarajan, B.S., Ed., Mechanisms of Molecular Migrations, Interscience, New York 1968, Vol. 1 pp. 121 - 156; Paquette, L. A. Accounts Chem. Res. 1 (1968) 209; Bordwell, F. G. In Janssen, M. J., Ed., Organosulfur Chemistry, Interscience, New York 1967, Chapter 16; Bordwell, F. G. Accounts Chem. Res. 3 (1970) 281.

10. Bordwell, F. G., Williams, Jr., J. M., Hoyt Jr., E. B. and Jarvis, B. B. J. Amer. Chem. Soc. 90 (1968) 429.

11. Opitz, G. and Fischer, K. Angew. Chem. $7 \%$ (1965) 41; Angew. Chem. Int. Ed. Engl. 4 (1965) 70.

12. Aichenegg, P. C. U. S. Patent $3,109,032$ (1963); Chem. Abstr. 60 (1964) 2769.

Received January 26, 1974. 